\title{
ALTERACIONES FISIOLÓGICAS Y ENZIMÁTICAS EN SEMILLAS DE TRIGO (Triticum aestivum L.) RECUBIERTAS CON SILICIO
}

\author{
Lizandro Tavares ${ }^{1}$, Lilian Tunes ${ }^{1}$, André Mendonça ${ }^{1}$, Elisa Lemes ${ }^{1}$, Jadiyi Salinas ${ }^{1}$, Antonio \\ Carlos Barros ${ }^{1}$, Géri Meneghello ${ }^{1}$ \\ ${ }^{1}$ Universidade Federal de Pelotas, Departamento de Fitotecnia, E-mail: lizandro_cicilianotavares@yahoo.com.br, \\ lilianmtunes@yahoo.com.br, andreh_mendonca@hotmail.com, lemes.elisa@yahoo.com.br, j_s@yahoo.com.br, \\ acbarros@ufpel.edu.br,gmeneghello@gmail.com
}

\section{RESUMEN}

El silicio es uno de los micronutrientes más importantes para el cultivo del arroz (Oryza sativa) y el objetivo de este estudio fue evaluar las alteraciones en los estándares de calidad fisiológica y enzimática de semillas de trigo (Triticum aestivum L.) recubiertas con diferentes dosis de silicio. Las dosis más elevadas de silicio no afectaron la calidad fisiológica de las semillas, pero redujeron la tasa de pérdida de viabilidad de las semillas. Las variaciones electroforéticas de las isoenzimas estuvieron asociadas al tratamiento de semillas de trigo, donde se destacaron las enzimas esterasa y fosfatasa ácida.

Palabras-clave: electroforesis, isoenzimas, tratamiento de semillas, Triticum aestivum, vigor

\section{ALTERAÇÕES FISIOLÓGICAS E ENZIMÁTICAS EM SEMENTES DE TRIGO RECOBERTAS COM SILÍCIO}

\section{RESUMO}

O silício é um dos micronutrientes mais importantes para o cultivo de arroz (Oryza sativa) e o objetivo deste estudo foi avaliar as mudanças na qualidade fisiológica e enzimática de sementes de trigo (Triticum aestivum L.) tratadas com diferentes doses de silício. As maiores doses de silício não afetaram a qualidade fisiológica das sementes, mas reduziu a taxa de perda de viabilidade das sementes. As variações eletroforéticas das isoenzimas estão associadas com o tratamento das sementes de trigo, onde as enzimas esterase e fosfatase ácida se destacaram.

Palavras-chave: eletroforese, isoenzimas, tratamento de sementes, Triticum aestivum, vigor 


\section{INTRODUCCIÓN}

Agregar valor a las semillas usando métodos y tecnologías de producción, tales como su recubrimiento, es una exigencia del mercado. Para ello se necesitan semillas con alta uniformidad de germinación/emergencia (vigor) y que produzcan plántulas con alto potencial de crecimiento (BAUDET \& PESKE, 2004). La nutrición de las plantas, especialmente la utilización de nutrientes como silicio $(\mathrm{Si})$ mediante el tratamiento de semillas, contribuye a la sostenibilidad del sistema de producción (MARSCHNER, 1995).

La fertilización con macro y micronutrientes es una técnica que contribuye a obtener alta productividad en los cultivos. Entre los micronutrientes más importantes para el cultivo de arroz (Oryza sativa), está el $\mathrm{Si}$, el cual aumenta el crecimiento y desarrollo de la planta así como la productividad, además de controlar varias enfermedades de este cultivo (SAVANT et al., 1997). El uso de Si promueve mejoras en la arquitectura de la planta y aumento en la fotosíntesis, debido a la menor abertura del ángulo foliar, que hace que las hojas estén más erectas, disminuyendo el auto sombreado, lo cual deriva en un mejor aprovechamiento de la energía lumínica (DEREN et al., 1994).
La electroforesis se usa para estudiar las isoenzimas en relación con los cambios en la calidad fisiológica de las semillas, y también en relación a las regulaciones génicas y bioquímicas (ISTA, 1992). Las isoenzimas son producto de la expresión génica y están altamente influenciadas por el ambiente y el manejo, ya que los genes que controlan su expresión se manifiestan en ciertos estadios del desarrollo y en órganos y tejidos específicos, o por un estímulo específico (RAMÍREZ et al., 1991). Las isoenzimas son variaciones de una enzima dentro de un organismo que presentan una misma especificidad de sustrato. La intensidad de las bandas en electroforesis con gel enzimático es específica en cada una de ellas, para una determinada parte de la planta, tejido y etapa de desarrollo de la misma (MALONE et al., 2006).

Las enzimas más investigádas relacionadas con la calidad fisiológica de las semillas són la esterasa, la fosfatasa ácida, la deshidrogenasa y la peroxidasa (CARVALHO et al., 2000). La esterasa participa en las relaciones de hidrólisis de esteres y está directamente ligada al metabolismo de los lípidos, como los fosfolipidos totales de membrana (SANTOS et al., 2005). La enzima fosfatasa ácida tiene la función de hidrolizar los fosfomonoesteres 
de numerosas reacciones químicas vegetales, entre ellas, la formación de sacarosa durante la fotosíntesis (TANKSLEY, 1983). La enzima peroxidasa incluye un grupo de enzimas que catalizan la transferencia del hidrógeno de un donador para $\mathrm{H}_{2} \mathrm{O}_{2}$ durante la germinación de las semillas y en las etapas de crecimiento (MENEZES et al., 2004). La enzima glutamato deshidrogenasa es responsable de la oxidación de aminoácidos, proporcionando energía para el ciclo de Krebs, producción de NADPH o en la reducción de $\alpha$-cetoglutarato para la síntesis de aminoácidos (VIEIRA et al., 2009).

El objetivo de este estudio fue evaluar las alteraciones en los padrones de calidad fisiológica y enzimática de semillas de trigo recubiertas con diferentes dosis de silicio.

\section{MATERIALES Y MÉTODOS}

El estudio se realizó en diciembre de 2012 en el Laboratorio de Semillas y Biosemillas del Departamento de Fitotecnia, Facultad de Agronomía Eliseu Maciel, Universidad Federal de Pelotas, en PelotasRS, Brasil.

El diseño experimental fue completamente aleatorio y los tratamientos fueron $0,1.0,2.0,3.0$ y 4.0 g Microton ${ }^{\circledR} \mathrm{kg}^{-}$ ${ }^{1}$ de semillas (Microton ${ }^{\circledR}$ es un compuesto de silicato mineral, que consiste en filosilicatos), representando $26 \%$ de Si, con ocho repeticiones. La variedad de trigo utilizada fue FUNDACEP 52. Las semillas se recubrieron con el polímero Sepiret ${ }^{\circledR}$ y agua $\left(2.5 \mathrm{~mL} \mathrm{~kg}^{-1}\right.$ de semillas $)$ para optimizar la adherencia del producto a la semilla. El recubrimiento de las semillas se realizó manualmente, utilizando 200 g de semillas por repetición; la mezcla de los productos se realizó en bolsas plásticas y después se agregaron las semillas. Éstas fueron agitadas hasta conseguir la completa distribución de los productos y la cobertura de las semillas, y luego éstas fueron secadas a temperatura ambiente durante $24 \mathrm{~h}$.

La calidad fisiológica de las semillas se determinó por la prueba de germinación, el primer conteo de germinación, la longitud de plántulas y la prueba de envejecimiento acelerado.

Prueba de germinación (PG): Se usaron cuatro repeticiones de 100 semillas sembradas en rollos de papel toalla (Germitest) humedecidas con agua destilada, en la proporción de 2.5 veces el peso del papel seco, y a $20{ }^{\circ} \mathrm{C}$. El primer conteo (PCG) se realizó 4 d después de la instalación, y el último, $8 \mathrm{~d}$ después de la siembra (dds). Los resultados fueron 
expresados en porcentaje de plántulas normales (BRASIL, 2009).

Longitud de plántulas: La longitud de la parte aérea (LPA) y la de la raíz (LR) de las plántulas se determinaron con una regla graduada en $\mathrm{mm}$. La longitud media de la parte aérea se obtuvo sumando las medidas de cada repetición por tratamiento y dividiendo por el número de plántulas normales; los resultados se expresaron en cm (KRZYZANOWSKI et al., 1999).

Prueba de envejecimiento acelerado (PEA): La PEA se realizó usando cajas de plástico transparente (tipo gerbox), con 40 $\mathrm{mL}$ de agua y una bandeja de tela de aluminio donde las semillas, después de ser pesadas $(3 \mathrm{~g})$, fueron distribuidas formando una camada uniforme. Las cajas se mantuvieron $72 \mathrm{~h}$ en cámaras tipo BOD a $41^{\circ} \mathrm{C}$; después se usaron cuatro sub muestras de 100 semillas en una prueba de germinación, según la metodología descrita anteriormente, y el conteo 4 dds (MARCOS FILHO, 1999).

Para el estudio de la diferenciación isoenzimática, la siembra se realizó en canteros de $6 \mathrm{~m} \times 1 \mathrm{~m}$, siendo las plántulas de trigo cosechadas 14 días después de la siembra. Las isoenzimas analizadas fueron: esterasa (EST), fosfatasa ácida (ACP), glutamato deshidrogenasa (GTDH), malato deshidrogenasa (MDH) e peroxidasa (PO).

Para la extracción de estas isoenzimas, la parte aérea de diez plántulas elegidas al azar se cosechó y maceró en morteritos de porcelana. De cada una de las muestras, $200 \mathrm{mg}$ de ese macerado se colocaron en un tubo Eppendorf con agregados de solución extractora (tampón

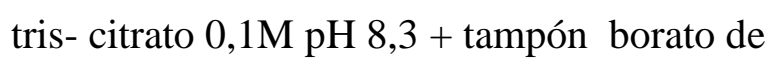
litio $0,1 \mathrm{M} \mathrm{pH} 8,3+0,15 \%$ de 2 mercaptoetanol) 1:2 (p/v). La electroforesis fue realizada en geles de poliacrilamida al 7 $\%$, colocando $20 \mu \mathrm{l}$ de cada muestra en agujeros hechos con el auxilio de un peine de acrílico. Se realizaron tres aplicaciones (repeticiones) para cada una de las muestras.

Los padrones enzimáticos se analizaron por medio del 1 sistema de tampones descrito por Scandálios (1969). Los productos en estado de gel se colocaron en cubas electroforéticas verticales, mantenidas a temperatura ambiente. Las migraciones electroforéticas fueron realizadas con una diferencia de potencial de $10 \mathrm{~V} . \mathrm{cm}^{-1}$, hasta que la línea de frente formada por el azul del bromofenol alcanzara el nivel inferior del gel. Los geles fueron desarrollados para los sistemas enzimáticos mencionados (SCANDALIOS, 
1969; ALFENAS, 1998) y fijados en una solución de glicerol al $10 \%$.

Los datos se sometieron a análisis de varianza $(p \leq 0,05)$; con una probabilidad significativa "F", se hizo la regresión polinominal. Para la interpretación de los resultados de la electroforesis, el análisis visual del gel fue de presencia/ausencia, y también se evaluó la intensidad de cada una de las bandas electroforéticas en cada sistema isoenzimático.

\section{RESULTADOS Y DISCUSIÓN}

No hubo diferencia significativa en el primer conteo de germinación ni en la germinación de semillas de trigo recubiertas con silicio (Figura 1A e 1B). La germinación en todas las dosis analizadas fue superior a $80 \%$, siendo elevada para los padrones de semillas, donde el mínimo exigido es de 80 $\%$ (BRASIL, 2004). Estos resultados demuestran que las semillas de trigo pueden ser utilizadas como medio de transporte de silicio sin afectar la calidad fisiológica de las semillas. Resultados semejantes fueron encontrados por Santos et al. (2010) en semillas de Brachiaria y por Toledo et al. (2011) en semillas de avena blanca. Sin embargo, la investigación de Matichenkov et al. (2005) con semillas de trigo, detectaron un aumento lineal en el test de germinación y en el primer conteo con dosis más elevadas de silicio. De acuerdo con Korndörfer et al. (2001), el tratamiento de semillas con silicio influye en el desarrollo de las semillas indirectamente, aumentando el rendimiento de los lotes.

Para la prueba de longitud de la parte aérea y raíz (Figura 2A e 2B), las diferentes dosis analizadas de silicio no presentan diferencias. Resultados semejantes fueron obtenidos por Toledo et al. (2011) para la variable longitud de la parte aérea en semillas de avena blanca.

Los efectos positivos del tratamiento de las semillas con $\mathrm{Si}$ en relación a su calidad han sido estudiados por algunos autores, como Datnoff et al. (1997), Balastra et al. (1989) y Deren et al. (1994), especialmente en el control de enfermedades, fertilidad de las espiguetas y masa de semillas, respectivamente. Sin embargo el silicio parece influir en otras características, además de la germinación y la longitud de las plántulas, como ocurrió en este experimento. 


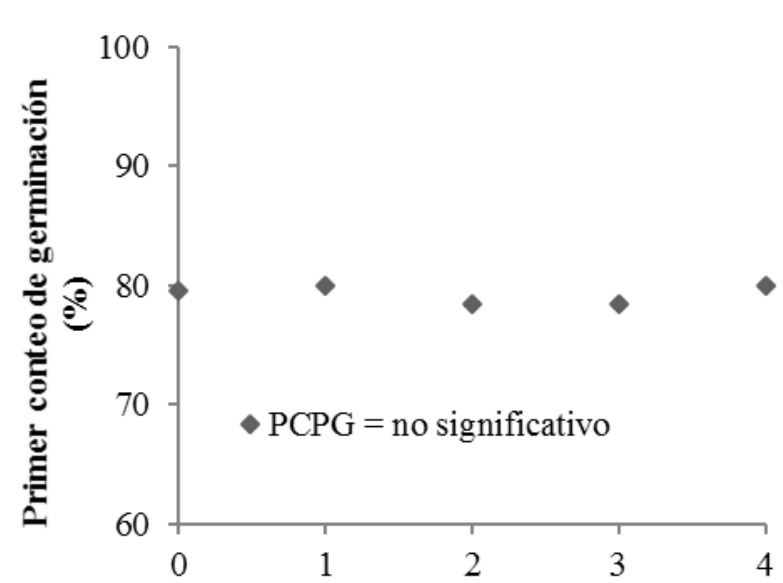

A Dosis de Microton ( $\mathrm{g} \mathrm{kg}^{-1}$ de semillas)

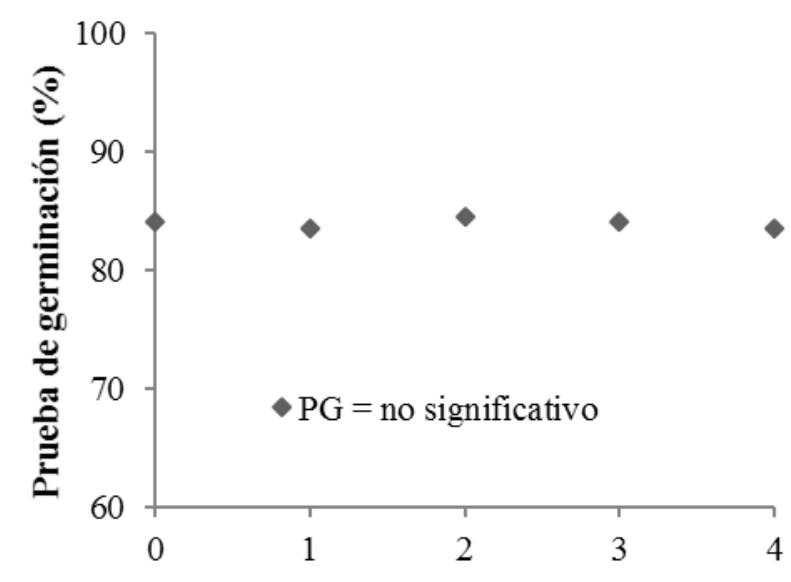

B Dosis de Microton ( $\mathrm{g} \mathrm{kg}^{-1}$ de semillas)

Figura 1. Primer conteo la prueba de germinación - PCG (1A) y prueba de germinación - PG (1B) en semillas de trigo recubiertas con 0, 1.0, 2.0, 3.0 y 4.0 gramos de Microton ${ }^{\circledR}$ (Silicio) por kg de semillas.

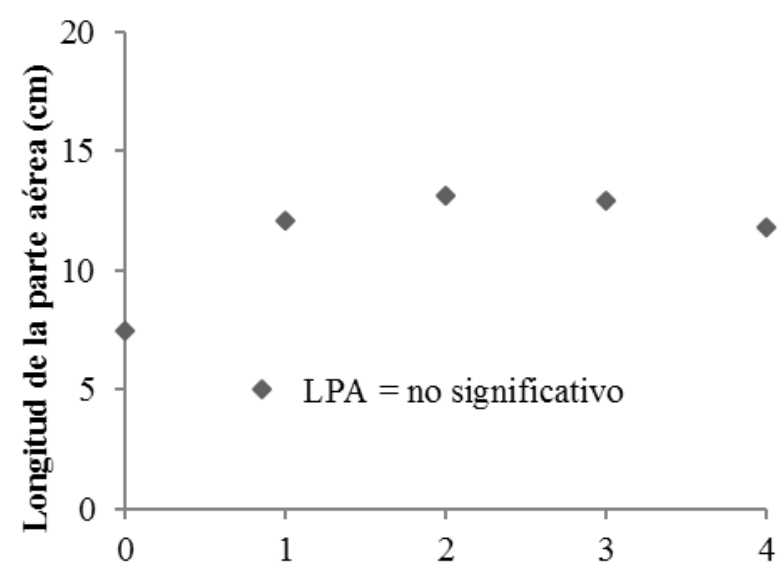

A Dosis de Microton ( $\mathrm{g} \mathrm{kg}^{-1}$ de semillas)

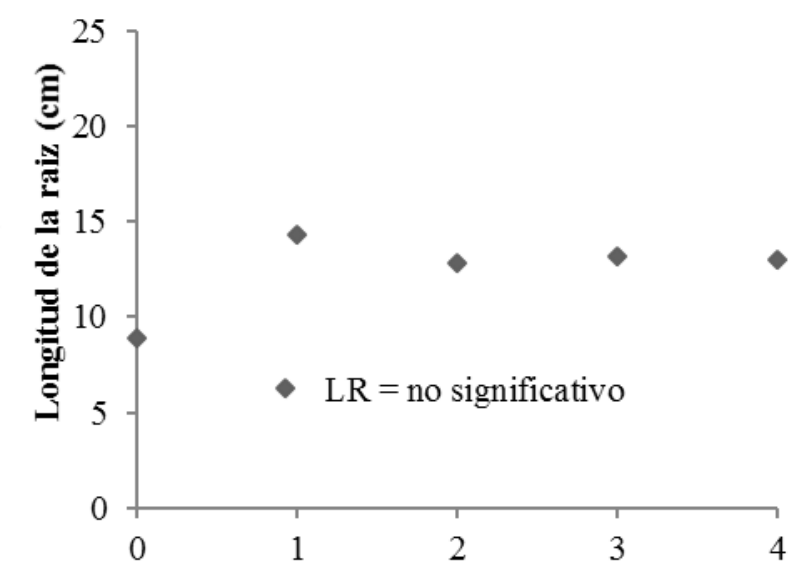

B Dosis de Microton ( $\mathrm{g} \mathrm{kg}^{-1}$ de semillas)

Figura 2. Longitud de la parte aérea - LPA (2A) y longitud de la raíz - LR (2B) en semillas de trigo recubiertas con $0,1.0,2.0,3.0$ y 4.0 gramos de Microton $^{\circledR}$ (Silicio) por kg de semillas.

En la Figura 3, se encuentran los resultados de la germinación obtenidos después de la prueba de envejecimiento acelerado (PEA). Se puede observar una diferencia entre las dosis probadas en las semillas de trigo en función del potencial fisiológico. El mejor rendimiento fue obtenido con las dosis de 3,0 y 4,0 g. $\mathrm{kg}^{-1}$ de semillas con silicio, permitiendo así, clasificarlas como las de mayor vigor. 
La prueba de envejecimiento acelerado consiste en evaluar la respuesta de las semillas después de ser sometidas a condiciones adversas por un determinado periodo de tiempo (ROSSETO \& MARCOS FILHO, 1995). Esto se basa en el hecho de que la tasa de deterioro aumenta considerablemente cuando las semillas son expuestas a tales condiciones. Así se verifica que las dosis más elevadas de silicio promueven una menor pérdida de viabilidad cuando las semillas son sometidas al test de envejecimiento acelerado. De acuerdo con Rafi et al. (1997), la presencia de silicio puede resultar en un aumento de la capacidad biológica de las semillas y plántulas para resistir las condiciones adversas del medio ambiente. Además de las semillas, estudios científicos han demostrados aumentos significativos en la tasa fotosintética, mejoras en la arquitectura foliar y otros procesos en el metabolismo vegetal de las plantas, teniendo como resultado final un aumento de y una mejor calidad en la producción (SRIPANYAKORN et al., 2005).

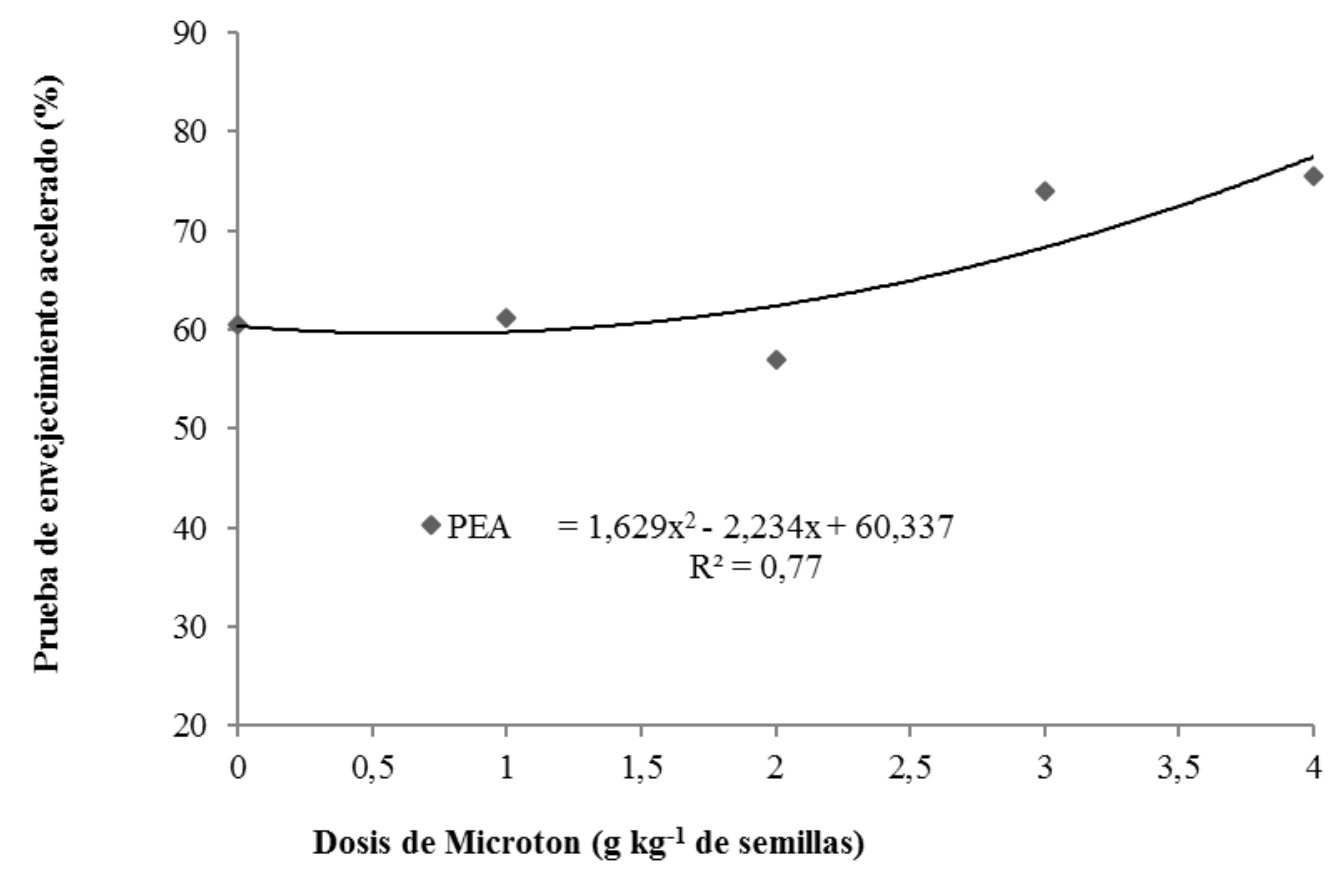

Figura 3. Prueba de envejecimiento acelerado - PEA en semillas de trigo recubiertas con 0, 1.0,

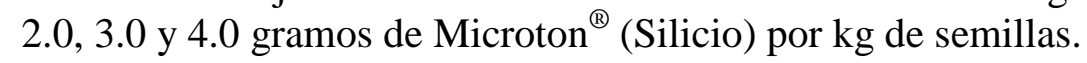




\begin{abstract}
Según Marschner (1995), la utilización del silicio se vuelve particularmente interesante cuando se le considera como un anti estresante. El estrés causado por temperaturas extremas, por ejemplo, puede tener un efecto menor con el uso de silicio. Puede también aumentar la resistencia a varias enfermedades causadas por hongos, como también a algunas plagas.
\end{abstract} En Brasil, se ha difundido su uso en los últimos años, principalmente después de su inclusión como micronutriente en la legislación de los fertilizantes por el Ministerio de Agricultura (BRASIL, 2004). Este hecho ha generado un creciente interés entre técnicos y agricultores por los innumerables beneficios que proporciona a los cultivos, como el aumento en la productividad y resistencia al estrés abiótico y biótico.

El tratamiento de semillas con silicio no afecta el rendimiento fisiológico de las plántulas de trigo, pero puede ser una alternativa viable, promoviendo una protección de las semillas frente al estrés, como ocurre en el test de vigor (envejecimiento acelerado).

En el análisis de los cinco sistemas enzimáticos utilizados fue posible visualizar que hubo una variación significativa en la intensidad de la expresión isoenzimática, de acuerdo al aumento en la concentración de silicio en las semillas (Figuras 4, 5 y 6). Con base en dicha variación, cada sistema fue estudiado y analizado individualmente.

La expresión de la enzima esterasa presentó bandas menos intensas en las dosis más altas de silicio en el tratamiento de semillas de trigo (Figura 4). La esterasa es una enzima responsable del metabolismo de lípidos de membranas durante la germinación de semillas; por ello, se observa que hubo un efecto negativo de los productos aplicados. Las alteraciones en los padrones de esa enzima evidenciaron deterioros, ya que la esterasa es una enzima que participa en reacciones de hidrólisis de esteres, estando directamente relacionada con el metabolismo de lípidos (TUNES et al., 2010). De acuerdo con Malone et al. (2007), esa variación también puede deberse a un metabolismo más acelerado, sugiriendo que la mayor parte de los materiales de reserva ya habían sido metabolizados a los catorce días de germinación. Así esa reducción puede atribuirse no sólo al tratamiento de las semillas con silicio, sino que también al periodo en que se recolectaron muestras para el análisis.

La expresión de las enzimas de fosfatasa acida (FAC) se puede ver en los diferentes tratamientos con silicio (Figura 4). 
Se detectaron bandas de FAC en todos los tratamientos evaluados; sin embargo, a medida que aumentó la concentración de silicio, hubo disminución en su intensidad. Esa enzima participa en reacciones de hidrólisis de esteres y puede provocar la peroxidaccion de los fosfolipidos de membranas. Según Camargo et al. (2000), también toma parte en el mantenimiento del fosfato celular y su actividad puede afectar el metabolismo del fosfato en semillas, como los niveles de ATP y nucleótidos. Autores como Vieira (2000) y Brandão Junior et al. (1999) solamente analizaron la actividad de la fosfatasa ácida en las semillas de maíz y algodón, que se presentaban en avanzado grado de deterioro.

Analizando el perfil electroforético del sistema glutamato deshidrogenasa
(GTDH) (Figura 5), no se observó variación en la intensidad de bandas entre las diferentes dosis de silicio. Esta enzima actúa en la oxidación de aminoácidos (proteínas de reserva), proporcionando energía a las células (ciclo de Krebs) y/o reduciendo el $\alpha$ cetoglutarato en la síntesis de los aminoácidos. Ésta probablemente desempeña un importante papel en la germinación de las semillas, proporcionando energía al proceso, o aminoácidos para el desarrollo del embrión. Según Brandão Junior et al. (1999), esta enzima presenta una alta correlación entre la reducción de la actividad y la pérdida de la calidad fisiológica de las semillas. Este hecho no fue detectado en este estudio, donde se obtuvieron datos de germinación y primer conteo de germinación similares.

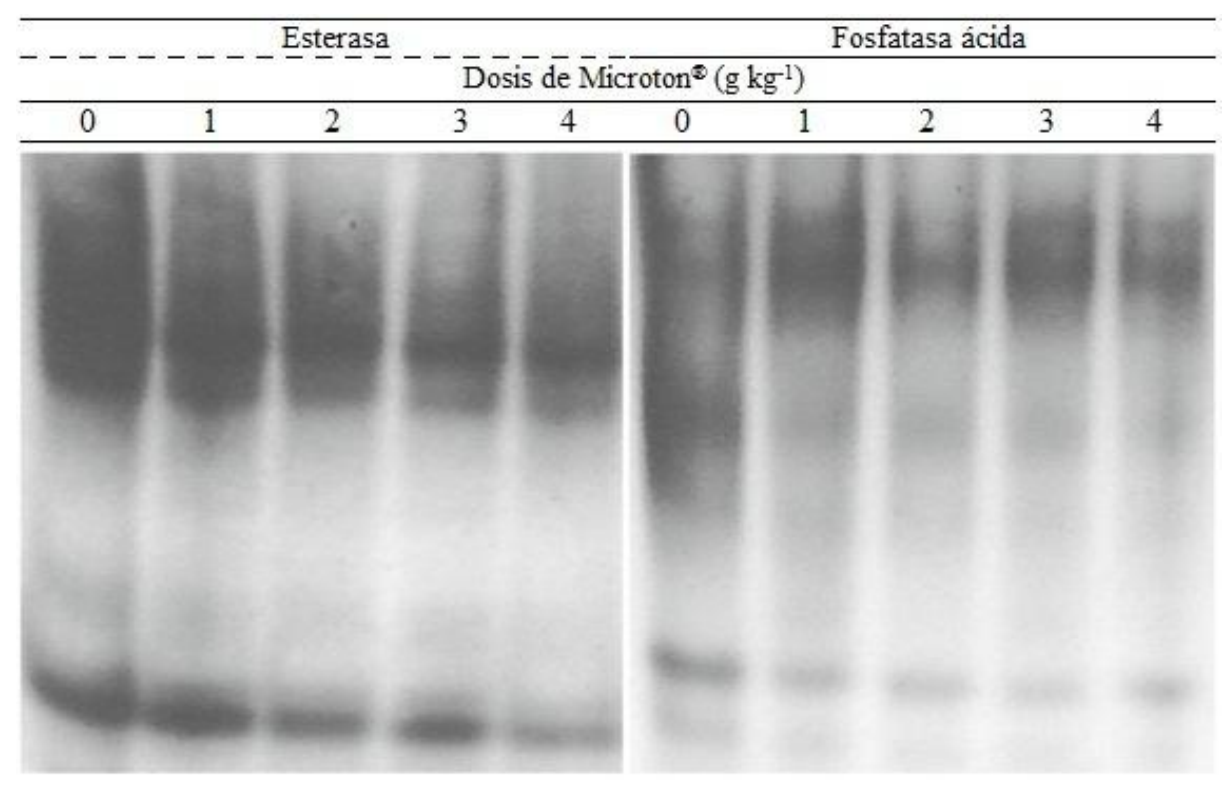

Figura 4. Padrón electroforético obtenido con el sistema isoenzimático esterasa y fosfatasa ácida en semillas de trigo recubiertas con dosis de Microton ${ }^{\circledR}$ (Silicio). 
Otras deshidrogenasas estudiadas fueron la malato deshidrogenasa (Figura 5). Esta enzima cataliza la última reacción del ciclo de Krebs, oxidando el malato a oxaloacetato y produciendo la conversión de malato a oxaloacetato, teniendo una importante función de producción de NADH para el Ciclo de Krebs y la generación de oxaloacetato para la biosíntesis de aminoácidos. Su expresión no presentó diferencia entre las dosis probadas de silicio en semillas de trigo, por la misma hipótesis planteada para la enzima GTDH, donde no se presentan diferencias significativas en los tests de calidad fisiológica.

En la Figura 6, se presenta el sistema isoenzimático peroxidasa (PO), onde la expresión de la enzima no fue alterada por la utilización de diferentes dosis de silicio en el tratamiento de semillas en relación al testigo.
Sin embargo, según el estudio de Gomes et al. (2008), las semillas que fueron recubiertas con silicio presentaron una mayor actividad de la peroxidasa. La peroxidasa utiliza el peróxido de hidrógeno para oxidar una gran variedad de sustancias donadoras de hidrogeno, como los fenoles, anillos aromáticos, diaminas, ácido ascórbico, aminoácidos y algunos ácidos inorgánicos (NKANG, 1996). Su expresión puede ser alterada considerablemente por la temperatura y el $\mathrm{pH}$. La actividad de esta enzima varía según el tipo de tejido y la etapa vegetativa de desarrollo de la planta, siendo su expresión inversamente proporcional al crecimiento del individuo; de esta forma, su presencia podría ser observada en otra fase de desarrollo del material vegetal analizado, que viene de las semillas tratadas.

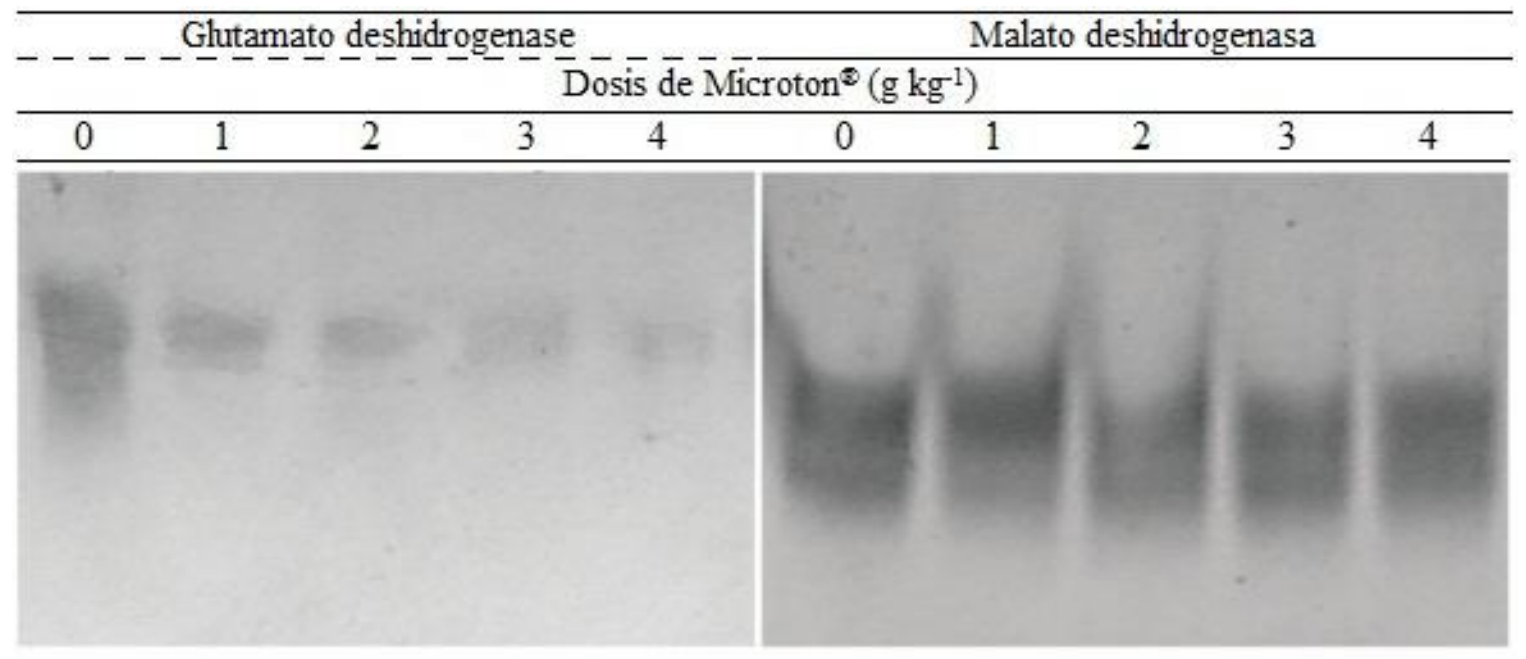

Figura 5. Padrón electroforético obtenido con el sistema isoenzimático glutamato deshidrogenase y malato deshidrogenasa en semillas de trigo recubiertas con dosis de Microton ${ }^{\circledR}$ (Silicio). 


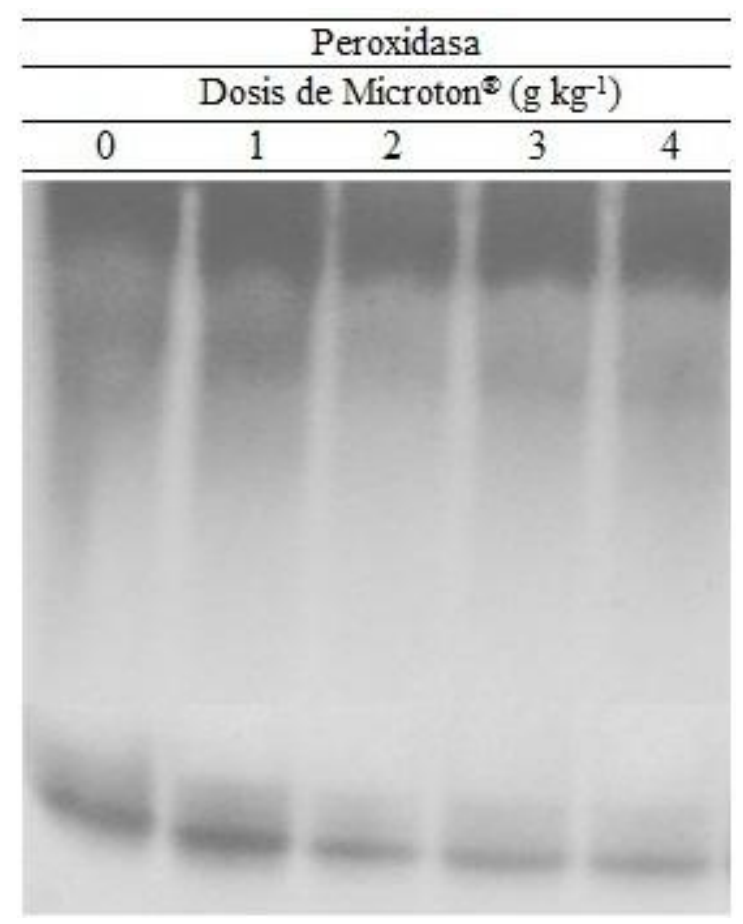

Figura 6. Padrón electroforético obtenido con el sistema isoenzimático peroxidasa en semillas de trigo recubiertas con dosis de Microton ${ }^{\circledR}$ (Silicio).

De los cinco diferentes sistemas enzimáticos estudiados, los de la enzima esterasa (EST) y la fosfatasa ácida (FAC) se revelaron como promisorios marcadores bioquímicos para la evaluación de calidad de las semillas de trigo en las ocasiones en que fueron tratadas con silicio. Se detectaron alteraciones en el perfil electroforético de las plántulas que, sometidas a diferentes dosis de silicio, revelaron variaciones en el nivel de calidad.

Los resultados obtenidos en el presente trabajo sugieren que, dependiendo del sistema enzimático utilizado, existe una diferencia en las proteínas. Por ese motivo, el análisis conjunto de varios sistemas enzimáticos es recomendable porque permite verificar modificaciones que ocurren en el interior de las semillas cuando son sometidas a algún tipo de tratamiento que influya en su calidad.

\section{CONCLUSIONES}

En el tratamiento de semillas, las dosis más elevadas de silicio no afectan la calidad fisiológica de las semillas; Por ello, dichas dosis de silicio promueven menores reducciones en la viabilidad de las semillas.

Las variaciones electroforéticas de isoenzimas están asociadas al tratamiento de semillas de trigo, destacándose las enzimas esterasa y fosfatasa acida. 


\section{LITERATURA CITADA}

ALFENAS, A.C. 1998. Eletroforeses de Isoenzimas e Proteínas Afins: Fundamentos e Aplicações em Plantas e Microrganismos. Viçosa: Universidade Federal de Viçosa. 574 p.

BALASTRA, M.L.F.; PEREZ, C.M.; JULIANO, B.O.; VILLREAL, P. 1989. Effects of silica level on some proprieties of Oryza sativa straw and hult. Canadiam Journal of Botany, Guelph, v.67, 2356-2363.

BAUDET, L.; PESKE, F. 2004. Aumentando o desempenho das sementes. Seed News, Pelotas, 5: 22-24.

BRASIL. 2004. Regulamento da lei 6894 de 16 de janeiro de 1980 , que dispõe sobre a inspeção e físcalização da produção e do comércio de fertilizantes, corretivos, fertilizantes, inoculantes ou biofertilizantes destinados a agricultura, e dá outras providências. Normas Jurídicas (Texto integral) - DEC 004954.14 de jan.pp: 27.

BRASIL. 2009. Regras para análise de sementes. Ministério da Agricultura, Pecuária e Abastecimento, Brasília, 399 p.

CARVALHO, M.L.M.; VIEIRA, M.G.G. C.; PINHO, E.R.V. 2000. Técnicas moleculares em sementes. Biotecnologia. Ciência \& Desenvolvimento, Brasília, v. 3., n.17, p.44-47.

DATNOFF, L.E.; DEREN, C.W.; SNYDER, G.H. 1997. Silicon fertilization for disease management of rice in Florida. Crop Protection, London, v.16, n.6, p.525-531.

DEREN, C.W.; DATNOFF, L.E.; SNYDER, G.H.; MARTIN, F.G. 1994. Silicon concentration, disease response, and yield components of rice genotypes grown on flooded organic histosols.
Crop Science, London, v.34, n.2, p.733737.

GOMES, F.B.; MORAES, J.C.; CUSTÓDIO, D.S.; ANTUNES, C.S. 2008. Uso de silício como indutor de resistência em batata a Myzus persicae (Sulzer) (Hemíptera: Aphididae). Neotropical Entomology, Londrina, v.37, n.2, p.180-190.

International Seed Testing Association. ISTA. 1992. Handbook of Variety Testing: Electrophoresis Testing, Zürich: ISTA. 50 p.

KORNDÖRFER, G.H.; SNYDER, G.H.; ULLOA, M.; POWELL, G.; DATNOFF, L.E. 2001. Calibration of soil and plant silicon analysis for rice production. Journal of Plant Nutrition, New York, v.24, n.4, p.1071-1084.

MALONE, G.; ZIMMER, P.D.; CASTRO, M.A.S.; CARVALHO, I.; MENEGHELLO, G.E.; PESKE, S.T. 2006. Identificação do estádio adequado para realização de análises isoenzimáticas na caracterização de cultivares de trigo. Revista Brasileira de Sementes, Pelotas, v.28, p.193-200.

MALONE, G.; ZIMMER P.D.; MENEGHELLO G.E.; CASTRO M.A.S.; PESKE, S.T. 2007. Expressão diferencial de isoenzimas durante 0 processo de germinação de sementes de arroz em grandes profundidades de semeadura. Revista Brasileira de Sementes, Londrina, v.29, n.1, p.61-67.

MARCOS FILHO, J. 1999. Testes de vigor: importância e utilização. In: KRZYZANOWSKI, F.C; VIEIRA, R.D; FRANÇA NETO, J.B. Vigor de Sementes: Conceitos e Teses. Londrina, cap.1, p.1-21.

MARSCHNER, H. 1995. Mineral nutrition of higher plants. Academic. London. $889 \mathrm{p}$.

MATICHENKOV, $\quad$ V.V.; KOSOBRUKHOV, A.A.; SHABNOVA, N.I.; BOCHARNIKOVA, E.A. 2005. 
Plant response to silicon fertilizers under salt stress. Agrokhimiya, Moscow, v.10, p.59-63.

MENEZES, S.M.; TILLMANN, M.A.A.; DODE, L.B.; VILLELA, F.A. 2004. Detecção de soja geneticamente modificada tolerante ao glifosato por métodos baseados na atividade de enzimas. Revista Brasileira de Sementes, Pelotas, v.26, n.2, p.150-155.

NKANG, A. 1996. Effect of cyanide pretreatment on Peroxidase activity in germinating seeds of Guilfoylia monostylis. Journal of Plant Physiology, Stuttgart, v.149, n.1,p.3-8.

RAFI, M.M.; EPSTEIN, E.; FALK. R.H. 1997. Silicon deprivation causes physical abnormalities in wheat (Triticum aestivum L.). Journal of Plant Physiology, Stuttgart, v.151, n.4, p.497501.

RAMÍREZ, H.; CALDERON, A.; ROCCA, W. 1991. Técnicas moleculares para evaluar y mejorar el germoplasma vegetal. In: Rocca, W.; Mroginski, L. (Ed). In: Cultivo de Tejidos en la Agricultura: Fundamentos y aplicaciones. CIAT. Cali. pp: 825-856.

SANTOS, C.M.R.; MENEZES, N.L.; VILLELA, F.A. 2005. Modificações fisiológicas e bioquímicas em sementes de feijão no armazenamento. Revista Brasileira de Sementes, Pelotas, v.27, n.1, p.104-114.

SANTOS, F.C.; OLIVEIRA, J.A.; VON PINHO, E.V.R.; GUIMARÃES, R.M.; VIEIRA, A.R. 2010. Tratamento químico, revestimento e armazenamento de sementes de Brachiaria brizantha cv. Marandu. Revista Brasileira de Sementes, Londrina, v.32, n.3, p.069078.

SAVANT, N.K.; SNYDER, G.H.; DATNOFF, L.E. 1997. Silicon management and sustainable rice production. Advances in Agronomy, San Diego, v.58, p.151-199.
SCANDALIOS, J.G. 1969. Genetic control of multiple molecular forms of enzymes in plants: a review. Biochemical Genetics, New York, v.3, p.37-39.

SRIPANYAKORN, S.; JUGDAOHSINGH, R.; THOMPSON, R.P.H.; POWELL, J.J. 2005. Dietary silicon and bone health. Nutrition Bulletin, Oxford, v.30, n.3, p.222-230.

TANKSLEY, S.D. 1983. Isozymes. Part B. Elsevier. Amsterdam. 472 p.

TOLEDO, M.Z; GARCIA, R.A.; MERLINA, A; FERNANDES, D.M. 2011. Seed germination and seedling development of white oat affected by silicon and phosphorus fertilization. Scientia Agricola, Piracicaba, v.68, n.1, p.18-23.

TUNES, L.M.; PEDROSO, D.C.; MENEGHELLO, G.E.; CASTRO, M.A. S.; BARROS, A. C.S.A.; BADINELLI, P.G.; MUNIZ, M.F.B. 2010. Perfil enzimático em sementes de cevada em resposta a diferentes concentrações salinas. Interciência, Caracas, v.35, n.5, p.369-373.

VIEIRA, E.H.N.; YOKOYAMA, M. 2000. Colheita, processamento e armazenamento. In: VIEIRA, E.H.N.; RAVA, C.A. Sementes de feijão: produção e tecnologia. Santo Antônio de Goiás: Embrapa Arroz e Feijão. pp: 233-248.

VIEIRA, E.S.N.; VON PINHO, E.V.R.; CARVALHO, M.G.G.; SILVA, P.A. 2009. Caracterização de cultivares de soja por descritores morfológicos e marcadores bioquímicos de proteínas e isoenzimas. Revista Brasileira de Sementes, Londrina, v.31, n.1, p.86-94.

Recebido em: 05\02\2014 Aceito para publicação em: 26\11\2014 